\title{
The Influence of Advertising Media towards Consumer Purchasing Behavior in the Food and Beverage Industry in Malaysia
}

\author{
Ong Choon Hee (Corresponding author) \\ Azman Hashim International Business School, \\ Universiti Teknologi Malaysia, 81310 Johor Bahru, Johor, Malaysia \\ E-mail: ongchoonhee@gmail.com \\ Woon Say Yen \\ Azman Hashim International Business School, \\ Universiti Teknologi Malaysia, 81310 Johor Bahru, Johor, Malaysia \\ E-mail: karlwoon91@gmail.com
}

Received: Mar. 13, 2018 Accepted: Apr. 3, 2018 Online published: Apr. 4, 2018

doi:10.5296/ijhrs.v8i2.12877ＵRL: https://doi.org/10.5296/ijhrs.v8i2.12877

\begin{abstract}
This paper aims to analyze the relationship between print service advertising, broadcast advertising, social media advertising and consumer purchasing behavior. Focusing on the role of advertising media in enhancing consumer purchasing behavior, the research was set in the context of Malaysian food and beverages industry. The respondents consisted of consumers of the food and beverages outlets in Johor Bahru, Johor, Malaysia. A quantitative cross sectional survey method was adopted, coupled with factor analysis and multiple regression analysis to analyze the collected data. The findings of this study revealed that print service advertising, broadcast advertising and social media advertising were positively and significantly related to consumer purchasing behaviour. Further, social media advertising was found to be the strongest predictor of consumer purchasing behavior. The findings of this research facilitate food and beverages operators to identify the appropriate method of advertising to capture the attention of consumers and subsequently increase their market share.
\end{abstract}

Keywords: print service advertising, broadcast advertising, social media advertising, 
consumer purchasing behavior

\section{Introduction}

\subsection{Background of the Study}

Advertising is interpretation in terms of audio or visual form of marketing communication that employs an openly sponsored, non-personal message to promote or sell a product, service, or idea. Throughout the centuries ago, advertising has been used to promote goods and services that market wish to sell to the public. Since then, advertising has involved with presenting messages to attract potential customers. Nowadays, there are a lot of advertising channel which using a medium used by an organization to advertise their products (MBA Skool, 2017) and inform the customers about promotion such as print advertising, broadcast advertising, covert advertising, outdoor advertising, surrogate advertising, celebrity advertising and print service advertising (Nartey, 2010). These advertising methods do only have two purposes, brand recognition and promoting goods and services (Porter \& Claycomb, 1997). As time goes by, advertisers have to change their methods of advertisement to retain their customers and attract new customers. In the other hand, they do also have to take note of how consumer behavior is changing over the time. Consumers are the end user for the products where they keep the production cycle moving which holds important role in the economic system of any nation (Ampofo, 2014). In order to gain attention of the consumers, advertisers have to aware the demands of the consumers from time to time (Ampofo, 2014). Thus, advertising methods grow as well from print service advertising to social network advertising. The purpose of advertisement is to increase sales revenue and profits of firms and increase the demand for goods that has been decreasing gradually (Ampofo, 2014). Advertising has tremendously changed consumer purchasing behavior by giving the consumers a good source of information where consumers are more influenced with advertised products (Rashid \& Sidin, 1987). Advertisement with pictures feature in online advertisement has strongest influence to create purchase intention. Besides that, advertising have significant positive effect on brand loyalty (Hanaysha, 2016). It also helps the firm to create perceived favorable image which is likely become a customer value as well (Hanaysha, 2016). The essential part of doing advertisement is to reach out to consumers and competitors, showing its presence on the market and is one of a key aspect in marketing communication element (Hanaysha, 2016). Broadcast, social media, and print advertising should be keep it active to reach out consumers whereas it has influence towards consumers (Haque, Rahman, Ahmed, Yasmin, \& Asri, 2011). Thus, this research will provide confirmation that advertisement through various channels would be beneficial to the organization or it is a futile effort. Besides that, this research will show various channel of advertisement such as broadcasting advertisement, print advertisement and internet advertisement will be able to influence consumer behavior without consideration of age difference.

\section{Literature Review}

\subsection{Consumer Purchasing Behavior}

Consumer purchasing behavior is about how individuals, groups, and organizations to select, 
purchase, use and disposal of products, services, ideas, or experiences to meet the consumers' demand (Shih, Yu, \& Tseng, 2015). It is a study of ways of buying and disposing of goods etc. to satisfy their needs and wants (Dudovskiy, 2013). Consumer is someone can either be an individual or an organization who is the end user of the goods or the services whichever available in the market. A consumer has the right and the power to make the decision about purchasing goods or services and this action or plan of making the purchase is called consumer behavior. There are four main factors that influence consumer purchases, which are personal, cultural, social, and psychological (Educba, 2016). Firstly, personal factors such as age, occupation, income, and lifestyle are actually will affect consumer behavior. It is obvious that people buy different products at their different stages of life cycle as singles, married couples, unmarried couples, or senior citizen. Consumer preference will change with the change of age and the life cycle as time goes by (Khaniwale, 2015). Next, the occupation of the individual also influences the individual's buying behavior. The buying considerations and decisions are different according to their profession and role in the society (Brosekhan, Velayutham, \& M.Phil, 1998). Moreover, the financial or economic situation of consumers will affect their purchase power as well because income is an importance source of purchasing power. The more the income of the person, then the more will be the expenditure on other items. As the income of the individual is higher, then the spending power of the individual increases as well. Besides that, the purchase pattern of consumers differs according to their different lifestyle. Individual who have higher spending power will pursue branded products which have appeared in various advertising channels (Zhang, 2015). Next, culture of the consumer will affect the consumer behavior when it makes purchases. A research shows that Muslim culture will purchase the product based on the advises from other's opinion while Chinese will make purchases based on individual opinion without less consulting on other opinion (Lai, Chong, Sia, \& Ooi, 2010). Third, for the social factor, different social class will have different opinion on making decision to purchase the product whereas higher social class will purchase advertised and branded products while lower social class will purchase the goods that fulfil the needs of the individual (Rani, 2014). Finally, for the psychological factors, organization should develop its social media component as consumers are part of social networks that influence their online perception and trust in a certain website through word-of-mouth (Cetină, Rădulescu, \& Munthiu, 2012). It is important that advertisers have to obtain the knowledge between advertising and consumer such as how advertising affects and how consumer behavior reacts. Understanding consumer decision-making is essential for companies and advertisers in coming up with appropriate marketing strategies by following the regulation to suit their target groups (Muniady, Mamun, Permarupan, \& Zainol, 2014). Yet, one of the essential problems of organizations is the knowledge of how to tackle consumers that will be used for achieving their ultimate goal of advertising (Deshwal, 2016). Therefore, based on the above explanation, there is a need to examine the influence of advertising media towards consumer purchasing behavior.

\subsection{Print Service Advertising}

Print service advertising is the method to promote the product, service or message via magazine, poster, newspaper, brochure and etc. to reach customers. Throughout the long 
history, print service advertising has been used to spread messages to the customers with the purpose of spreading awareness. It is worth to advertise using paper to give impact to customer perceptions (Hampel, Heinrich, \& Campbell, 2012). As when there is an impact of advertisement to customer perception for print service advertising, advertising using newspaper, poster, and magazine is still a demand to give awareness to potential customers (Nayak \& Shah, 2015). Newspaper is the media that produce information in many forms of media and it often rated as less effective marketing tool (Ladd, 2010). Nevertheless, newspapers have been experiencing declining circulation figure and lessening advertising revenues for several years where it poses threat to existing newspaper press (Lindstädt \& Budzinski, 2012). Based on the analysis conducted by Lindstädt and Budzinski (2012), some businesses cannot use newspaper advertising anymore such as business retailers, shopping centers and catalog showroom. Meanwhile, advertising of some other industries are replaced by other advertising media such as internet advertisement, television advertisement, or traditional advertisment (Lindstädt \& Budzinski, 2012). In a nutshell, newspaper advertisement will be served as niche market in current market (Lindstädt \& Budzinski, 2012). According to Cuhadar (2005) advertising effectiveness of internet is lower than newspaper advertising. However, the awareness spread by internet advertising is much higher than newspaper (Çuhadar, 2005). Internet advertisement was considered more disturbing compared to print advertisement which explains why effectiveness of internet advertisement is much lower than print advertisement (Numberger \& Schwaiger, 2003). Therefore, using internet advertisement alone is far less effective than print advertisement (Numberger \& Schwaiger, 2003). Nevertheless, advertising using print service have different effect from different field of organizations. According to Bansal \& Gupta (2014), the effect can be surveyed from the way that promotions with more educational substance were found to impact a greater number of clients than ads with less instructive substance. Thus, print service advertisement is still popular approach for advertisers to use for advertisement. The content in print service advertisement conveys direct message to consumers and the effectiveness for consumer to receive the message is also accurate (Manchanda, Dube, Goh, \& Chintagunta, 2006). In addition, consistency of a print advertisement increases purchasing behavior from consumers (Manchanda, Dube, Goh, \& Chintagunta, 2006). Certainly, the arrangement of advertisement such as verbal or pictorial material is important to form up an advertisement (Janiszewski, 1990). Based on the above rational explanation, it is hypothesized that:

H1: There is a significant relationship between print advertising and consumer purchasing behavior.

\subsection{Broadcast Advertising}

Broadcast advertising is a method that organization uses to advertise by using television or radio, and known as air advertising. Goods and services marketers do receive different responses of effectiveness between promoting products and services (Gauci \& Hill, 2003). Today, advertising companies invest huge amounts of their earnings in advertising in different media such as television, radio, and magazine as television is one of the widespread media for this purpose (Ansari \& Joloudar, 2011). In broadcast advertising, there are certain regulation needs to be followed. The regulation is divided into several environmental factors 
such as types of media, restriction on certain products, adverting images, social forces, and government restrictions (Waller D. S., 1993). Thus, advertisers have to consider the environmental factors in order to produce advertisement to the audience and also able to convey the message to the targeted audience. Today, advertising companies invest huge amounts of their earnings in advertising in different media such as television, radio, magazine and etc. that television is one of the prevalent media for this purpose Many persuasive messages will be created to persuade the audience and it does not have an initial effect, but changes in behavior take place after a period of time (Gerber, Terblanche-Smit, \& Crommelin, 2014). It was predicted that positive impacts of TV advertisement are on customers' attention to advertisement, interest for purchasing, desire for purchasing, action of purchasing and customers' satisfactions. There are some channels that the audience are young people where it associated with lowered rates if advertising avoidance in broadcast advertising (Wilbur, 2016). For radio advertising, it is a powerful advertising medium because it is the most assessable whether in a car, working in a field or cooking dinner (Balya, 2008). Besides that, it is immediate as they reach faster than newspaper or on television and it is inclusive where it reaches most people includes poor, marginalized or those who cannot read or write (Balya, 2008). According to Contemporary Communications (2017), Consumers spent two-and-a-half hours listening to radio a day where radio has consumed $10 \%$ of their time; hence radio advertising is an alternative for advertiser to consider. Besides that, radio advertising is cost effective compared with newspaper advertising and radio is an uncluttered medium. Broadcast advertising can help to build brand introduction and securing brand recognition. Brand introduction should be started early because time will gradually improve brand recall in consumers (Gerber, Terblanche-Smit, \& Crommelin, 2014). Television advertising can maximize brand recognition and influence consumers to know and remember the brand that was advertised (Gerber, Terblanche-Smit, \& Crommelin, 2014). However, the cost for television advertising is high and the message may not always reach to target audience where advertisers have to take note between selecting advertising media and approach (Budacia, 2012). Thus, it is important to create a good advertising as Malaysian consumer agree with factor that advertisement is proving information about product and purchasing behavior (Samy, 2015). Based on the above discussion, it is hypothesized that:

$\mathrm{H} 2$ : There is a significant relationship between broadcast advertising and consumer purchasing behavior.

\subsection{Social Media Advertising}

- Social Media is a term that is widely used nowadays in connecting people from all over the world. Social Media is the democratization of information, transforming people from content readers into content publishers. It is the shift from a broadcast mechanism to a many-to-many model, rooted in conversations between authors, people, and peers. (Neti, 2011). Social media advertising will have certain impact on consumer's response on the product. It can be either positive or negative, depends on ways of the product being presented to consumer. The message that the advertiser intends to convey will be different as the consumer will have different perspective. It shows the advertising is getting more essential lately. 


\section{Ml Macrothink}

International Journal of Human Resource Studies

ISSN 2162-3058

2018, Vol. 8, No. 2

Social media will definitely have some impacts to digital environment. Internet, television, and virtual communities have transformed the consumers with wider choice in been touch with people and products from all over the world. Same situation happens to household as well. The social media technologies within the home are leading to increased social isolation and a privatization of people's lives within the household (McGrath, 2012). This clearly shows the big impact of the social media on people's life and advertisement. Mobile advertising is one of the technologies which will impact the advertisement as people no longer need to sit in front of computer to place any booking to any of the product. This can be done via mobile phone setting, as long as there is an internet connection. This will increase consumer's spending as people no longer require checking on the advertisement and understanding the message sent by advertiser with their desktops. They can do it via mobile phones. Online WOM is the most-represented topic in digital and social marketing research, which is unsurprisingly given the consumers' reliance on socially sourced online information (Stephen, 2015). This is obviously seen as the impact of social media towards digital environment with technology given the consumers the power to investigate products, label and criticize them in equal measure and more. Therefore, many companies today have pages on social networks to complement the information held about the products, held by the feedback of consumers about the products and tend to relate more to the company after reading various reviews (Ioanăs, 2014). In a nutshell, social media advertising has impacts on consumer purchasing behavior. Therefore, it is hypothesized that:

H3: There is a significant relationship between social media advertising and consumer purchasing behavior.

\section{Methodology}

\subsection{Participants}

The targeted participants for this study was residents residing in Johor Bahru, Johor, Malaysia. The citizens resided in Johor Bahru has a population of approximately 803,000 (World Population Review, 2017). The participants in Johor Bahru are suitable because this study is pointing to the demographic profiles where they have exposure on various media of advertisement. Thus, by assessing their knowledge and information on the independent variables of advertising media and their purchasing behaviours, this enables the researchers to complete the research study more accurately. The groups of participants include students, employees, self-employed personnel, professional, and those unemployed. They are the samples which possess purchasing power and their attitude towards advertising media is essential for this study. In the current food and beverage industry, competition is intense and every participant will give a significant input on what advertisers should advertise and use which channel to reach the potential customers. In order to collect data from the population of 803,000, sampling technique will be applied owing to time and cost limitation for this research. 


\subsection{Method and Instruments}

This study employed quantitative cross sectional survey method. Convenience sampling was chosen for this research. According to Saunders et al. (2012), convenience sampling is a form of random sampling which also known as availability sampling. The population size of this research is approximately 803,000 and according to the sampling table provided by Krejcie \& Morgan (1970). The required sample size for this population is 384 with $95 \%$ confidence and $5 \%$ margin of error. (Krejcie \& Morgan, 1970). The measures of consumer purchasing behaviour were adapted from Sivanesan (2016). Measures for print service advertising, broadcast advertising and social media advertising were adapted from Sivanesan (2014), Lee (2015) and Awan (2016). Likert scale was used to measure the level of agreement for print service advertising, broadcast advertising, social media advertising and consumer purchasing behaviour. The scale was anchored by 1 (Strongly disagree), 2 (Disagree), 3 (Neither agree nor disagree), 4 (Agree) and 5 (Strongly agree).

\subsection{Data Analysis}

Data analysis in the present study was conducted using Statistical Package for Social Science (SPSS). Factor analysis was selected to test the validity of the constructs and to assess how well the results obtained from the use of the measures represent the concept being measured (Sekaran and Bougie, 2010). Separately, multiple regression analysis was used to examine the relationship between advertising media and consumer purchasing behaviour.

\section{Results}

\subsection{Profile of the Respondents}

The questionnaires were distributed via Google form which targeted to reach 400 participants who are staying in Johor Bahru, but only managed to receive 397 responses which yield a response rate of more than $90 \%$. For this research, the researcher has gathered set of personal characteristics such as gender, age, income and qualification. From the responses received, 232 are female respondents and 165 are male. Majority of the respondents were aged between 20-29 years old and have a total of 194, which represent $48.9 \%$ of the respondents. Respondents aged above 50 were 46, aged below 20 were 44, aged from 30-39 were 62 and there were 51 respondents aged 40-49. For the income level of respondents, Malaysians were categorized into B40, M40 and T20. For monthly household income below RM 3000, it is categorized as B40, monthly household income between RM 3000 to RM 6275 belongs to M40, and more than RM 6275 is named T20. From the statistics received, $46.9 \%$ of the respondents were categorized as $\mathrm{B} 40,36.3 \%$ of the respondents as M40 and $16.9 \%$ of the respondents were T20. As for the qualification of the respondents, majority of them possess diploma and above which constitutes $74.8 \%$ of the respondents whereas the rest were possessing professional certificate or high school certificate.

\subsection{Factor Analysis}

The independent and dependent variables were validated using factor analysis. Table 1 depicts the results of Kaiser-Meyer-Olkin (KMO) and Bartlett's Test for the study variables. 


\section{Mll Macrothink}

International Journal of Human Resource Studies

ISSN 2162-3058

2018, Vol. 8, No. 2

The values of Kaiser-Meyer-Olkin for Measuring of Sampling Adequacy (KMO/MSA) were 0.887 and 0.883 for advertising media and consumer purchasing behavior. All the KMO values had reached the minimum value of 0.6 for a good factor analysis (Hair, Black, Babin, and Anderson, 2010; Pallant, 2007). The Bartlett's Test of Sphericity was statistically significant at the 0.001 level, thus supported the factorability of the correlation matrix.

\subsection{Advertising Media}

The principal component analysis (PCA) with varimax rotation extracted three (3) components from advertising media after cross loadings were deleted and factor loading of 0.35 and below were discarded. The rotated factors captured a total of $71.366 \%$ of the variance in which component 1 contributes $24.796 \%$, followed by component 2 at $23.977 \%$, and component 3 at $22.593 \%$. Drawing on the factor analysis results (see Table 2), items that loaded on component 1 ( 5 items) were labeled print service advertising, component 2 (5 items) was named social media advertising and component 3 (5 items) were classified as broadcast advertising.

Table 1. Kaiser-Meyer-Olkin (KMO) and Bartlett's Test for Study Variables

\begin{tabular}{ccc}
\hline Factorability Assessment & Advertising Media & $\begin{array}{c}\text { Consumer Purchasing } \\
\text { Behavior }\end{array}$ \\
\hline Kaiser-Meyer-Olkin (KMO) & 0.887 & 0.883 \\
Measure of Sampling Adequacy. & 4027.646 & 1192.676 \\
Bartlett's Test of Sphericity & 105 & 10 \\
Approx. Chi-Square & .000 & .000 \\
df & Sig. &
\end{tabular}

Table 2. Factor Analysis for Advertising Media

\begin{tabular}{|c|c|c|c|}
\hline \multirow[t]{2}{*}{ Items } & \multicolumn{3}{|c|}{ Factor Loading } \\
\hline & 1 & 2 & 3 \\
\hline $\mathrm{P} 2$ & 0.610 & & \\
\hline P5 & 0.846 & & \\
\hline P6 & 0.901 & & \\
\hline P7 & 0.868 & & \\
\hline P8 & 0.861 & & \\
\hline B1 & & & 0.811 \\
\hline B2 & & & 0.772 \\
\hline B3 & & & $0 / 802$ \\
\hline B5 & & & 0.745 \\
\hline B6 & & & 0.757 \\
\hline S1 & & 0.762 & \\
\hline $\mathrm{S} 2$ & & 0.847 & \\
\hline S3 & & 0.875 & \\
\hline S4 & & 0.736 & \\
\hline S5 & & 0.860 & \\
\hline Eigenvalues & 6.304 & 2.758 & 1.643 \\
\hline Percentage of Common variance & 24.796 & 23.977 & 22.593 \\
\hline Cumulative $\%$ & 24.796 & 48.774 & 71.366 \\
\hline Reliability Coefficient $(\alpha)$ & 0.902 & 0.900 & 0.882 \\
\hline
\end{tabular}




\subsection{Consumer Purchasing Behavior}

The principal component analysis (PCA) extracted 5 items that captured a total variance of $72.102 \%$ with an Eigenvalue of 3.605. The values of factor loading for customer-oriented behavior were in the range of 0.787 to 0.873 , whereas those factor loadings below 0.35 were discarded and cross loadings were deleted during the factor analysis. All the 5 items were loaded on a single factor and labelled as consumer-purchasing behavior. The results of the factor analysis were displayed in Table 3.

Table 3. Factor Analysis for Consumer Purchasing Behavior

\begin{tabular}{cc}
\hline Items & Factor Loading 1 \\
\hline CPB1 & 0.854 \\
CPB2 & 0.873 \\
CPB3 & 0.864 \\
CPB4 & 0.787 \\
CPB5 & 0.865 \\
\hline Eigenvalues & 3.605 \\
Percentage of Common variance & 72.102 \\
Cumulative \% & 72.102 \\
Reliability Coefficient $(\alpha)$ & 0.903 \\
\hline
\end{tabular}

\subsection{Reliability Test}

The reliability test results of independent variables and dependent variables were indicated in Table 1 and Table 2 respectively. The reliability coefficient (Cronbach's Alpha) for independent variables namely print service advertising, broadcast advertising and social media advertising was rated 0.902, 0.882 and 0.900 respectively. Cronbach's Alpha value for the dependent variable, consumer purchasing behavior is 0.903. All the measures were deemed reliable and consistent throughout the study as all values have exceeded the minimum value of 0.7 as suggested by Nunnally (1978) and DeVellis (2003). These statistical results confirmed the reliability of measurement scales used for this study.

\subsection{Correlation Analysis}

Pearson correlation analysis was employed to examine the correlation between consumer purchasing behavior and the independent variables namely print service advertising, broadcast advertising and social media advertising respectively. The results in Table 4 indicate a correlation between the dependent variable and independent variables. The results show that broadcast has the strongest correlation with consumer purchasing behavior among the four variables $(\mathrm{r}=0.603, \mathrm{p}<0.01)$ and both print service advertising $(\mathrm{r}=0.530, \mathrm{p}<0.01)$ ) and social media advertising $(\mathrm{r}=0.551, \mathrm{p}<0.01)$ were moderately correlated with consumer purchasing behavior. The correlation coefficients among the independent variables (i.e. print service, broadcast, social media) were ranged from 0.262 to 0.474 at the significance level of 0.01 . 
Table 4. Correlation between Advertising Media and Consumer Purchasing Behavior

\begin{tabular}{ccccc}
\hline & $\begin{array}{c}\text { Consumer } \\
\text { Purchasing } \\
\text { Behavior }\end{array}$ & $\begin{array}{c}\text { Print Service } \\
\text { Advertising }\end{array}$ & $\begin{array}{c}\text { Broadcast } \\
\text { Advertising }\end{array}$ & $\begin{array}{c}\text { Social } \\
\text { Media } \\
\text { Advertising }\end{array}$ \\
\hline $\begin{array}{c}\text { Consumer } \\
\text { Purchasing } \\
\text { Behavior }\end{array}$ & 1 & & & \\
$\begin{array}{c}\text { Print Service } \\
\text { Advertising }\end{array}$ & $.530^{* *}$ & 1 & & \\
Broadcast & $.603^{* *}$ & $.445^{* *}$ & 1 & \\
Advertising & & & & \\
Social Media & $.551^{* *}$ & $.262^{* *}$ & $.474 * *$ & 1 \\
Advertising & & & & \\
\hline
\end{tabular}

**Correlation is significant at the 0.01 level (2-tailed).

\subsection{Multiple Regression Analysis}

Table 5 shows that Multiple Linear Regression Analysis among independent variables and consumer purchasing behavior. The analysis shows that 52.8 percent $\left(\mathrm{R}^{2}=0.528\right)$ of the variance of consumer purchasing behavior can be explained by the three independent variables of advertising media. The analysis shows that print service advertising has a significant positive relationship with consumer purchasing behavior $(\beta=0.305, p<0.001)$. Therefore, $\mathrm{H} 1$ is accepted. Next, it was found that broadcast advertising $(\beta=0.315, \mathrm{p}<0.001)$ has a significant positive relationship with consumer purchasing behavior. Hence, $\mathrm{H} 2$ is accepted. On the other hand, it was discovered also social media advertising was positively associated with consumer purchasing behavior $(\beta=0.321, \mathrm{p}<0.001)$. Thus, $\mathrm{H} 3$ was supported. The regression results of the present study indicated that social media advertising contributed more towards consumer purchasing behavior with a standardized coefficient of $\beta=0.321$ if we compare with print service advertising and broadcast advertising. Therefore, social media advertising serves as the most effective media in generating consumer purchasing behavior.

Table 5. Multiple Regression Analysis among Independent Variable and Consumer Purchasing Behavior

\begin{tabular}{|c|c|c|c|c|c|c|}
\hline \multirow{2}{*}{$\begin{array}{l}\text { Independent } \\
\text { Variable }\end{array}$} & \multicolumn{4}{|c|}{ Consumer Purchasing Behavior } & \multirow{2}{*}{ Hypothesis } & \multirow{2}{*}{ Result } \\
\hline & beta, $\beta$ & Sig. & Tolerance & VIF & & \\
\hline $\begin{array}{l}\text { Print Service } \\
\text { Advertising }\end{array}$ & $0.305 * * *$ & 0.000 & 0.799 & 1.252 & $\mathrm{H} 1$ & Accepted \\
\hline $\begin{array}{l}\text { Broadcast } \\
\text { Advertising }\end{array}$ & $0.315 * * *$ & 0.000 & 0.665 & 1.505 & $\mathrm{H} 2$ & Accepted \\
\hline $\begin{array}{l}\text { Social Media } \\
\text { Advertising }\end{array}$ & $0.321 * * *$ & 0.000 & 0.772 & 1.296 & H3 & Accepted \\
\hline F value & 146.776 & & & & & \\
\hline R Square & 0.528 & & & & & \\
\hline
\end{tabular}

$* * *$ Significant at the 0.001 level, ** Significant at the 0.01 level, * Significant at the 0.05 
level

\section{Discussion}

The study provides greater understanding on the influence of advertising media towards consumer purchasing behavior in the food and beverages industry in Malaysia. Print service advertising was found to be significantly related to consumer purchasing behavior in this study. This finding is consistent with a research by Nayak and Shah (2005), stated that businesses such as restaurant, café and food and beverages outlets are still able to rely on print service advertising to influence its consumer purchasing behavior. Print service advertisers should not give up their business and continue to improve their business model in order to attract more clients in using print service advertising. However, according to Upadhyay (2014), print service advertising may not be as effective as other electronic media, but it is able to attract the elderly population and enhance their purchasing behavior. In order to improve the influence of print service advertising towards consumer purchasing behavior, the content of print service has to display more educational substance (Bansal \& Gupta, 2014). According to Lunden (2009), print service advertising has to blend with social media to maximize its influential capacity. Next, this study reveals that there is a significant relationship between broadcast advertising with consumer purchasing behavior. This finding is in line with the research conducted by Anjun (2015), where the researcher stated that broadcast advertising media has a strong relationship with consumer purchasing behavior and it is further supported by Siddiqui (2014). However, according to Gerber, Terblanche-Smit and Crommelin (2014), broadcast advertising was actually created to persuade the consumers where it takes place after a period of time and normally appears in the form of television and radio. Hence, most food and beverage outlets find it effective to boost their business after new recipe or menu has been introduced to recapitulate the attention of the consumers. On the other hand the findings of this study show that social media has the strongest relationship with consumer purchasing behavior $(\beta=0.321, \mathrm{p}<0.001)$. This finding is consistent with the research of Naidoo (2011), where the researcher revealed that social media advertisement shows better effectiveness in influencing consumer purchasing behavior. Social media advertising which was well-known with channels such as YouTube, Facebook, Tweeter and etc. get to reach consumers all around the globe. It is a shift from broadcast mechanism to a many-to-many model (Neti, 2011). In order for social media advertising to perform effectively, its brand must be established and possessed strong reputation among the consumers. However, it was also discovered that consumers have high attention and interest in broadcast advertising $(\beta=0.315, \mathrm{p}<0.001)$ which is relatively close to social media advertising. Broadcast advertising is the media which introduces brand recognition to consumers and instill a tagline or memory to consumers deeply. Therefore, food and beverages outlets should not ignore broadcast advertising as it poses great impact towards consumer purchasing behavior.

\section{Limitations and Future Study}

This research was conducted under certain limitations that have to be taken into consideration. The respondents were drawn from the city of Johor Bahru with regard to food and beverages 
setting only. The results may not able to generalize for the other cities in Malaysia. As such, it is suggested that future research may expand the study population and establish a broader research setting where it may cover the central or northern regions of the county and look into more channels of advertising towards enhancing consumer purchasing behavior. Future research may be conducted in order industries such as healthcare products, electrical appliances, garments, personal ornaments and automotive industry.

\section{Conclusion}

The primary focus of this research aims to discuss the influence of advertising media towards consumer purchasing behavior in the food and beverages industry. It was found that print service advertising, broadcast advertising and social media advertising were significantly related to consumer purchasing behavior. Social media advertising was discovered as the strongest factor in influencing consumer purchasing behavior. However, this study suggests that mixed advertising channels should be used to provide higher sense of reliability and persuasion in enhancing consumer purchasing behavior. Management should blend social media and broadcast advertising to have maximum effects and coverage to reach the targeted markets. The outcome of this research is expected to facilitate business owners to use the appropriate methods of advertising to capture the attention of consumers and subsequently increase their market share.

\section{Acknowledgements}

The authors wish to thank the Malaysian Ministry of Higher Education and Universiti Teknologi Malaysia (Vot: 14J81) for providing financial support to publish this paper.

\section{References}

Ampofo, A. (2014). Effects of Advertising on Consumer Buying Behaviour: With Reference to Demand for Cosmetic Products in Bangalore, India. New Media and Mass Communication, 48- 68. https://doi.org/10.2139/ssrn.2500915

Anjum, B., Irum, A., \& Naheed. (2015). Impact of Television Advertisement on Consumer Buying Behavior: The Moderating Role of Religiosity in the context of Pakistan. International Interdisciplinary Journal of Scholarly Research (IIJSR), 36-48.

Ansari, M. E., \& Joloudar, S. Y. (2011). An Investigation of TV Advertisement Effects on Customers' Purchasing and Their Satisfaction. International Journal of Marketing Studies, 175-181.

Awan, A. G., Ismail, M., Majeed, F., \& Ghazal, F. (2016). Effects of Advertisement on Consumer's Buying Behaviour with References to FMCGs in Southern Punjab-Pakistan. Journal of Marketing and Consumer Research, 23-30.

Balya, B. (2008). The Power of Radio: Basic Skills Manual. Friedrich-Ebert-Stiftung, 1-52.

Bansal, M., \& Gupta, S. (2014). Impact of Newspaper Advertisement on Consumer Behavior. Global Journal of Finance and Management, 669-674. 
Brosekhan, A. A., Velayutham, M., \& Phil, M. (1998). Consumer Buying Behaviour - A Literature Review. IOSR Journal of Business and Management, 08-16.

Budacia, A. (2012). ADVERTISING THROUGH TELEVISION. Holistic Marketing Management, 65-70.

Cetină, I., Rădulescu, V., \& Munthiu, M. C. (2012). Psychological and Social Factors that Influence Online Consumer Behavior. Procedia - Social and Behavioral Sciences, 184-188. https://doi.org/10.1016/j.sbspro.2012.09.029

Contemporary Communications. (2017). 10 Good Reasons to Advertise on Radio. Retrieved from Radio Advertising Facts: http://radioadvertisingfacts.com/the-facts/10-good-reasons-to-dvertise-on-radio/

Çuhadar, G. (2005). Printed Advertisement And Web Advertisement: A Comparative Study On Design Characteristics Of Both Media. Bilkent University, 1-98.

Deshwal, P. (2016). Online advertising and its impact on consumer behavior. International Journal of Applied Research, 200-204.

DeVellis, R. F. (2003). Scale development: Theory and applications (2nd ed.), California: Sage.

Dudovskiy, J. (2013, July 4). Consumer Buyer Behaviour Definition. Retrieved from Research Methodology: https://research-methodology.net/consumer-buyer-behaviour-definition/

Educba. (2016, April 25). 4 important Factors that Influence Consumer Behaviour. Retrieved from Educba: https://www.educba.com/4-factors-influencing-consumer-behaviour/

Gauci, D., \& Hill, R. (2003). Goods and Services Differences in Television Advertising: an Australian Replication. Australasian Marketing Journal, 11, 34-45. https://doi.org/10.1016/S1441-3582(03)70127-X

Gerber, C., Terblanche, S. M., \& Crommelin, T. (2014). Brand recognition in television advertising: The influence of brand presence and brand introduction. OpenJournals, 1-8. https://doi.org/10.4102/ac.v14i1.182

Hair, J. F., Black, W. C., Babin, B. J., \& Anderson, R. E. (2010). Multivariate data analysis. (7th ed.). New Jersey, Prentice Hall.

Hampel, S., Heinrich, D., \& Campbell, C. (2012). Is An Advertisement Worth the Paper It's Printed on? The Impact of Premium Print Advertising on Consumer Perceptions. Journal of Advertising Research, 1-10.

Hanaysha, J. (2016). The Importance of Social Media Advertisements in Enhancing Brand Equity: A Study on Fast Food Restaurant Industry in Malaysia. International Journal of Innovation, Management and Technology, 46-51.

Haque, A., Rahman, S., Ahmed, I. S., Yasmin, F., \& Asri, A. (2011). Assessing the impact of 
Advertisement towards Malay Consumers: an Empirical Study of Fast Food Restaurants in Malaysia. Business Management Dynamics, 39-53.

Ioanăs, E. (2014). Social Media and its Impact on Consumers Behavior. International Journal of Economic Practices and Theories, 295-303.

Janiszewski, C. (1990). The Influence of Print Advertisement Organization on Affect toward a Brand Name. Journal of Consumer Research, 53-65. https://doi.org/10.1086/208536

Khaniwale, M. (2015). Consumer Buying Behaviour. International Journal of Innovation and Scientific Research, 278-286.

Krejcie, R. V., \& Morgan, D. W. (1970). Determining Sample Size for Research Activities. Educational and Psychological Measuremen, 607-610. https://doi.org/10.1177/001316447003000308

Ladd, A. D. (2010). Developing Effective Marketing Materials: Newspaper and Magazine Print Advertising Design Considerations. Centre for Profitable Agriculture, 1-5.

Lai, F. S., Chong, S. C., Sia, B. K., \& Ooi, B. C. (2010). Culture and Consumer Behaviour: Comparisons between Malays and Chinese in Malaysia. International Journal of Innovation, Management and Technology, 180-185.

Lee, L. K. (2015). More Than 35\% Market Share In Malaysia; Revealing The Old Town Magic. Retrieved from Shares Investment: http://www.sharesinv.com/articles/2015/03/10/oldtown- malaysia-moat/

Lindstädt, N., \& Budzinski, O. (2011). Newspaper vs. Online Advertising - Is There a Niche for Newspapers in Modern Advertising Markets?. IME WORKING PAPER 113/11, 1-46. https://doi.org/10.2139/ssrn.1948487

Lunden, K. (2009). The Death of Print? The Challenges and Opportunities facing the Print Media on the Web. Reuters Institure for the Study of Journalism, 1-96.

Manchanda, P., Dube, J. P., Goh, K. Y., \& Chintagunta, P. K. (2006). The Effect of Banner Advertising on Internet Purchasing. Journal of Marketing Research, 98-108. https://doi.org/10.1509/jmkr.43.1.98

MBA Skool. (2017). Advertising Channel. Retrieved from MBA Skool: http://www.mbaskool.com/business-concepts/marketing-and-strategy-terms/10819-advertisin g- channel.html

McGrath, S. (2012). New Media Technologies in the Household. 64.

Muniady, R., Mamun, A. A., Permarupan, P. Y., \& Zainol, N. R. (2014). Factors Influencing Consumer Behavior: A Study among University Students in Malaysia. Asian Social Science, 18- 25. https://doi.org/10.5539/ass.v10n9p18

Naidoo, T. (2011). The effectiveness of advertising through the social media in Gauteng. 1-100. 
Nartey, G. K. (2010). The Effect Of Advertising On Consumer Behaviour: A Case Study Of MTN Ghana. Institute Of Distance Learning, 1-81.

Nayak, K., \& Shah, B. (2015). Effectiveness of Newspaper Print Ads. Indian Journal of Applied Research, 328-331.

Neti, S. (2011). Social Media and its oole in marketing. International Journal of Enterprise Computing and Business Systems, 16.

Numberger, S., \& Schwaiger, M. (2003). Cross Media, Print, and Internet Advertising: Impact of Medium on Recall, Brand Attitude, and Purchase Intention. EFOplan, 1-13.

Nunnally, J. C. (1978). Psychometric theory. New York: McGraw Hill.

Pallant, J. (2007). SPSS Survival Manual. England: McGraw-Hill.

Porter, S. S., \& Claycomb, C. (1997). The influence of brand recognition on retail store image. Journal of Product \& Brand Management, 373-387. https://doi.org/10.1108/10610429710190414

Rani, P. (2014). Factors influencing consumer behaviour. International Journal of Current Research and Academic, 52-61.

Rashid, Z. A., \& Sidin, S. (1987). The Attitudes of Malaysian Students towards Advertising. Analisis, 37-44.

Samy, C. R. (2015). Advertising: Product Information And Consumer Manipulation Factors Influenced Malaysian Consumers Buying Attitude. International Journal of Business, Economics and Law, 1-8.

Sekaran, U., \& Bougie, R. (2010). Research methods for business: A skill building approach (5th ed.). New York, NY: John Wiley \& Sons Ltd.

Shih, S., Yu, S., \& Tseng, H. (2015). The Study of Consumers' Buying Behavior and Consumer Satisfaction in Beverages Industry in Tainan, Taiwan. Journal of Economics, Business and Management, 391-394. https://doi.org/10.7763/JOEBM.2015.V3.215

Siddiqui, A. N. (2014). TV Ads Impact on Consumer Purchase Intention. International Conference on Marketing, 1-20.

Sivanesan, R. (2014). Impact of Brand image and advertisement on consumer buying behavior - Comparative study on rural and urban consumers. International Journal of Research in Management and Business Studies, 1(2), 73- 80.

Stephen, A. T. (2015). The Role of Digital and Social Media Marketing in Consumer. 46.

Upadhyay, I. B. (2014). Effectiveness of Print and Electronic media Advertisement: A Comparative Study. International Research Journal of Social Sciences, 23-28.

Waller, D. S. (1993). Cultural Values and Advertising in Malaysia. Asia Pacific Journal of Marketing and Logistics, 3-16. 
Wilbur, K. C. (2016). Advertising Content and Television Advertising Avoidance. Journal of Media Economics, 51-72. https://doi.org/10.1080/08997764.2016.1170022

World Population Review. (2017). Population of Cities in Malaysia (2017). Retrieved from World Population Review: http://worldpopulationreview.com/countries/malaysia-population/cities/

Zhang, Y. (2015). The Impact of Brand Image on Consumer Behavior. Open Journal of Business and Management, 58-62. https://doi.org/10.4236/ojbm.2015.31006

\section{Copyright Disclaimer}

Copyright for this article is retained by the author(s), with first publication rights granted to the journal.

This is an open-access article distributed under the terms and conditions of the Creative Commons Attribution license (http://creativecommons.org/licenses/by/4.0/). 